\title{
Comparison of Hemodialysis Using a Medium Cutoff Dialyzer versus Hemodiafiltration: A Controlled Cross-Over Study
}

This article was published in the following Dove Press journal: International Journal of Nephrology and Renovascular Disease

\author{
Anna Lindgren ${ }^{1,2}$ \\ Erik Fjellstedt iD $^{2,3}$ \\ Anders Christensson (iD) 2,3 \\ 'Department of Nephrology, Skåne \\ University Hospital, Lund, Sweden; \\ ${ }^{2}$ Department of Clinical Sciences Malmö, \\ Lund University, Malmö, Sweden; \\ ${ }^{3}$ Department of Nephrology, Skåne \\ University Hospital, Malmö, Sweden
}

Purpose: Conventional hemodialysis (HD) treatment has an acceptable removal of small uremic molecules, but so-called "middle molecules" in the range of $0.5-60 \mathrm{kDa}$ are poorly cleared with HD compared to a native kidney, which may contribute to morbidity in the dialysis population. Hemodiafiltration (HDF) has a better removal of middle molecules compared to HD but is technically demanding and requires well-functioning dialysis access. The newly introduced medium cutoff (MCO) filters have been developed to enhance middle molecule clearance in HD-mode. The aim of this study was to compare reduction ratios (RRs) of molecules with different molecular weights $(0.06-150 \mathrm{kDa})$ during dialysis with MCO dialyzer (used in HD-mode) compared to online-hemodiafiltration (ol-HDF) treatment with a conventional high-flux dialyzer.

Patients and Methods: This is a prospective controlled single-center cross-over study, including 16 patients in Malmö, Sweden. All patients had ongoing post-dilution ol-HDF treatment before the study. The study compared reduction ratios of small-, middle-, and large-sized molecules during a single $4 \mathrm{~h}$ dialysis treatment with post-dilution ol-HDF (Polyflux 210H) to a $4 \mathrm{~h}$ dialysis treatment with MCO dialyzer (Theranova 500) in HDmode. Between treatments, the patients had a washout period of at least two weeks of their ordinary HDF treatment to reach their ordinary steady state.

Results: ol-HDF had significantly higher RR for cystatin C (13 kDa), compared to MCO (RR 68.1 vs $65.8, p=0.003$ ), during a 4 h dialysis treatment (mean convection volume of 24.5 $\mathrm{L}$ for $\mathrm{HDF}$, and mean $\mathrm{Q}_{\mathrm{b}}$ of $324 \mathrm{~mL} / \mathrm{min}$ for $\mathrm{HDF}$ and $323 \mathrm{~mL} / \mathrm{min}$ for $\mathrm{MCO}$ ). There was no significant difference in the RR for other middle molecules, or for smaller or larger molecules.

Conclusion: Overall, the RRs were comparable for ol-HDF and MCO-HD. There was a slightly higher RR of cystatin $\mathrm{C}$ (a small middle molecule) for HDF compared to MCO but no difference in other measured molecules.

Keywords: chronic hemodialysis, dialysis, hemodiafiltration, hemodialysis, MCO, uremic toxins

\section{Introduction}

Conventional hemodialysis (HD) treatment has an acceptable removal of small $(<0.5 \mathrm{kDa})$ uremic molecules like urea, but so-called "middle molecules" in the range of $0.5-60 \mathrm{kDa}^{1}$ are poorly cleared with $\mathrm{HD}$ compared to a native kidney. It has been hypothesized that increased middle molecule clearance could lead to better survival/health. Hemodiafiltration (HDF) was invented to improve middle molecule clearance, since larger molecules have slow removal by diffusion compared to
Correspondence: Anna Lindgren ( Clinical Sciences Malmo, Lund University, SUS Malmö, Jan

Waldenströms Gata 15, Malmö SE-205

02 , Sweden

Tel +46-46-171698

Fax +46-40-337052

Email Anna.Lindgren@med.lu.se
International Journal of Nephrology and Renovascular Disease 2020:13 273-280 
small molecules, and are more dependent on convective transport for removal. There is some weak evidence that HDF with high convection volumes (above 17-23 L) lowers cardiovascular mortality compared to HD. ${ }^{2-4}$ However, since middle molecule clearance is still inferior with HDF compared to a native kidney, new dialysis technology aims to further improve middle molecule removal. ${ }^{5}$

Removal of middle molecules is highly dependent on convective volume, but also on the pore size of the dialysis membrane, ie, the sieving coefficient must be high enough for the molecule to pass through the dialysis membrane. The total convective transport is a product of convection volume times the sieving coefficient $\left(K=Q_{u f} \times S\right)^{6}$. High cutoff (HCO) membranes with a higher pore size (high sieving coefficient) were introduced to the market, but due to unacceptably large albumin $(67 \mathrm{kDa})$ losses, they are unsuitable for long-term use. ${ }^{7}$ The large albumin loss is due to a large variability in pore size; high average mean pore size gives a few pores that are too large. Recent technology has allowed production of dialyzers with more uniformly distributed pores, and the newly introduced medium cutoff (MCO) dialyzer has, despite comparable average pore size, much less albumin leak due to more uniform pores. The sieving coefficient for albumin is 0.008 for the new MCO dialyzers, to be compared with 0.2 for HCO-dialyzers, and $<0.01$ for high-flux membranes. ${ }^{7}$ A recent safety study did not find any significant albumin decrease during 6 months use of MCO filters. ${ }^{8}$

The MCO dialyzers, which are used in HD-mode, achieve convective transport by internal convection, by varying the pressure gradient over the dialysis membrane to create a very high amount of backfiltration (approximately 7.6 L with $\mathrm{Q}_{\mathrm{b}} 300 \mathrm{~mL} / \mathrm{min}$, and $12.7 \mathrm{~L}$ with $\mathrm{Q}_{\mathrm{b}}$ $400 \mathrm{~mL} / \mathrm{min}){ }^{9}$ This internal convection thus gives a moderate convection volume despite no substitution fluid. Despite a lower convection volume than HDF (which often gives convection volumes $>23 \mathrm{~L}$ ), the combination of a moderately high internal convection volume with a higher sieving coefficient gives better performance on clearing middle molecules, compared to standard HD, and under some circumstances also better clearance than HDF.

Clinical studies have confirmed better reduction rate (RR) and clearance for middle molecules with MCO compared to high-flux HD. ${ }^{10-12}$ Comparisons between $\mathrm{MCO}$ and HDF have shown more mixed results. MCO has been superior to HDF in two studies, Kirsch et al ${ }^{10,11}$ (HDF convection volume $24 \mathrm{~L}$ ), and Reque et $\mathrm{al}^{13}$ (HDF convection volume $23.5 \mathrm{~L}$ ), but in two studies not, Maduell et $\mathrm{al}^{14}$ (convection volumes $\sim 33-35 \mathrm{~L}$ ), and Garcia Prieto et $\mathrm{al}^{12}$ (convection volume $28 \mathrm{~L}$ ), and in vitro study by Voigt et $\mathrm{al}^{15}$ (convection volume $24 \mathrm{~L}$ ), showed no difference in loss of coagulation factors. The conflicting results on middle molecule removal by $\mathrm{MCO}$ compared to HDF may at least partly be explained by different convection volumes used for the HDF, where MCO has not been superior to HDF with very high convection volumes. An observational long-term study comparing MCO and HDF (24.4 L mean convection volume) showed no difference between treatments. ${ }^{16}$ Some authors also make a distinction between smaller middle molecules $(0.5-15 \mathrm{kDa})$ and larger middle molecules $(15-60 \mathrm{kDa})$, where theoretically, MCO dialyzers should be superior especially for the larger middle molecules. ${ }^{17}$

Large molecules $>60 \mathrm{kDa}$ should be minimally filtered through dialysis filters (since they are designed to avoid albumin (67 kDa) leakage). However, large molecules can also be removed in dialysis by adsorption onto the dialyzer membrane. ${ }^{18}$ Albumin, transferrin and $\mathrm{IgG}$ have been shown to be major components of the protein coating on dialyzer membranes. ${ }^{19}$

We wanted to compare the RR for small $(<500 \mathrm{Da})$, middle $(500-60,000 \mathrm{Da})$ and large molecules $(>60,000$ Da), during a single dialysis of MCO vs standard HDF treatments.

\section{Patients and Methods}

\section{Study Design}

This is a prospective controlled, non-randomized, singlecenter cross-over study, including 16 patients at the Department of Nephrology, Skåne University Hospital, Malmö, Sweden. Eighteen patients were originally enrolled, but one was lost to follow-up due to transfer to another dialysis center and one died of causes unrelated to the dialysis. The study was designed to compare Reduction Ratios (RRs) during a single 4h-dialysis treatment with post-dilution ol-HDF (conventional high-flux filter) compared to MCO dialyzer in HD-mode. All included patients had ongoing maintenance with postdilution hemodiafiltration (HDF) as standard treatment. We aimed for a washout period of at least two weeks between treatments. The study was initially randomized, but due to practical considerations of the dialysis nurses, the order of the measurements (MCO first or HDF first) was finally non-randomly assigned to provide equal 
number in both cross-over groups. We compared Theranova 500 (MCO) dialyzer (Baxter Inc, Lund, Sweden), in HD-mode, vs Polyflux 210H (Baxter Inc, Lund, Sweden), using online HDF (ol-HDF). Dialysis monitors were Baxter, Artis Physio (Baxter Inc, Lund, Sweden).

The study was not blinded, neither to the patient, physicians, nurse or data analyst.

\section{Inclusion Criteria and Ethical Permission}

The patients included were stable dialysis patients at Skåne University Hospital, Malmö, Sweden, with ongoing treatment with ol-HDF (post-dilution). The patients had (at study inclusion) $\mathrm{CRP} \leq 30 \mathrm{mg} / \mathrm{L}$, and no myocardial infarction within 3 months. This study was approved by the Lund University Ethical Committee (registration no. 2017/830) and followed the Helsinki declaration. Written informed consent was obtained from all patients in the study.

The study has been registered in Clinicaltrials.gov, NCT03437538.

\section{Dialysis Session}

Blood samples were taken during a $4 \mathrm{~h}$ dialysis session, at time point $0,30,60,120,240$, and 243 minutes after treatment start, at blood inlet (arterial port, A), and at 30, 60,120 , and $240 \mathrm{~min}$ at blood outlet (venous port, V). The last sample in the blood inlet (arterial port) at time 243 was performed using the low-flow method to avoid the impact of potential access recirculation (waiting $30 \mathrm{sec}-$ onds after reducing the blood flow to $75 \mathrm{~mL} / \mathrm{min}$ and stopping the infusion pump). Dialysis flow was set to $550 \mathrm{~mL} / \mathrm{min}$ and blood flow was set to $325 \mathrm{~mL} / \mathrm{min}$. Convection volume goal was $>23 \mathrm{~L}$. Ultrafiltration was performed according to the need of the patient. Low molecular weight heparin (LMWH) was used according to individual usual prescription. All dialysis patients had a dialysis regimen between 3-5 times a week.

\section{Laboratory Measures}

We measured the following molecules at each time point: Small molecules: urea $(0.06 \mathrm{kDa})$, creatinine $(0.113 \mathrm{kDa})$, phosphate $(0.095 \mathrm{kDa})$.

Middle molecules: $\beta 2$-microglobulin $(11 \mathrm{kDa})$, cystatin C (13 kDa), myoglobin (18 kDa), beta-trace-protein $(25$ $\mathrm{kDa})$, troponin $\mathrm{T}(35 \mathrm{kDa})$.

Large/mixed molecules: albumin $(67 \mathrm{kDa})$, transferrin (80 kDa), IgG (150 kDa). Additionally, we measured hematocrit (EVF), plasma-protein (total), and transthyretin (prealbumin).

All blood samples were immediately sent to the chemical laboratory at Skane University Hospital, Malmö, Sweden, and analyzed according to routine methodology. $\beta 2$-microglobulin, beta-trace-protein and transthyretin were analyzed on a BNII ProSpec-system (Siemens) according to the manufacturer's instructions. Cystatin $\mathrm{C}$, myoglobin, troponin $\mathrm{T}$, albumin (immunochemical), transferrin and $\mathrm{IgG}$ were analysed on a Cobas system (ROCHE) according to the manufacturer's instructions.

\section{Statistical Analysis}

All statistical analyses were done using R, version 3.5.1. An unpaired $t$-test was used for comparison of intraindividual differences in RR, since a paired $t$-test is unsuitable in absence of carry-over effects. ${ }^{20}$ Testing for carry-over effects was performed as recommended by Wellek and Blettner. $^{20}$ An overall significance level of $\alpha=0.05$ was used. A Bonferroni-corrected threshold for multiple outcomes, based on 14 outcomes: $p=(\alpha / 14)=0.0036$, was used as significance threshold for the individual outcomes. ${ }^{21}$

\section{Calculations}

Reduction ratio $(\mathrm{RR})=(($ pre-dialysis-concentration[A0]post-dialysis-concentration[A240])/ pre-dialysisconcentration[A0]) X 100\%.

The RRs are based on concentrations in the arterial port (blood inlet) blood samples. One patient received a shorter dialysis and RRs for this patient is calculated based on the observations at 2 hours (which were available for both HDF and MCO treatment for the patient). This patient was excluded from the descriptive plots of convection volume in relation to RR (since the dialysis time affects not only convection volume but also diffusion).

The post-dialysis concentrations of middle molecules and large molecules were adjusted for hematocrit according to Schneditz et al: ${ }^{22}$

$$
\begin{gathered}
\mathrm{P}_{-} \text {corrected }=\mathrm{P} / \mathrm{h}_{\mathrm{p}} \\
\mathrm{h}_{\mathrm{p}}=\mathrm{H} 1\left(100-\mathrm{H}_{0}\right) / \mathrm{H}_{0}\left(100-\mathrm{H}_{1}\right)
\end{gathered}
$$

where $\mathrm{P}$ is the measured plasma concentration, $\mathrm{H}$ is hematocrit, and indices 0 and 1 are before and after dialysis (A0 and A240, respectively).

The study originally intended to calculate clearance based on arteriovenous difference at time points 30, 60, 120 and $240 \mathrm{~min}$. However, the blood samples taken in the 
venous port had a high variability (indicating nonreliability) and had to be discarded.

Missing data: albumin was missing at A240 for 1 patient, IgG at A0 for 1 patient, and total protein at A240 for 2 patients. RRs and mean values pre- and post-dialysis are calculated based on patients with no missing measurements for the analyzed molecule ( $n=15$ for albumin and $\operatorname{IgG}, n=14$ for total protein, $\mathrm{n}=16$ for all other molecules).

Dialysis vintage time was only approximately calculated. Year of dialysis start was known for all patients, but month of dialysis start (or month of dialysis restart after transplantation) was missing for 5 patients. For these, the start date was approximated to be in the middle of the year of dialysis start (1st of July).

\section{Results}

Descriptive results can be seen in Tables 1 and 2. The treatments had a mean convection volume of $24.5 \mathrm{~L}$ (for $\mathrm{HDF}$ ), mean blood flow of $324 \mathrm{~mL} / \mathrm{min}$ for $\mathrm{HDF}$ and $323 \mathrm{~mL} / \mathrm{min}$ for $\mathrm{MCO}$, and a dialysis flow of $550 \mathrm{~mL} / \mathrm{min}$ for all patients except one patient which had a dialysis flow of $500 \mathrm{~mL} / \mathrm{min}$ during the MCO-treatment. No carry-over effects were seen between treatments.

\section{Small Molecules}

No difference was seen between the reduction ratios for MCO and HDF for small molecules (Table 3).

Table I Description of the Patients $(n=16)$

\begin{tabular}{|l|l|l|}
\hline & & N (\%) \\
\hline $\begin{array}{l}\text { Cause of CKD } \\
\text { Disease) }\end{array}$ & $\begin{array}{l}\text { Diabetes } \\
\text { Polycystic kidney } \\
\text { disease } \\
\text { Other }\end{array}$ & $\begin{array}{l}7(44 \%) \\
2(12.5 \%)\end{array}$ \\
\hline Vascular access & $\begin{array}{l}\text { AV-fistula } \\
\text { Central venous } \\
\text { dialysis catheter }\end{array}$ & $\begin{array}{l}15(94 \%) \\
1(6 \%)\end{array}$ \\
\hline Urine production & $\begin{array}{l}\text { Anuric } \\
700-3000 \mathrm{~mL}\end{array}$ & $\begin{array}{l}\text { II (69\%) } \\
5(31 \%)\end{array}$ \\
\hline Age (years) & Mean \pm SD (range) \\
\hline Dialysis vintage (years) & & $59.6 \pm 12.9(34-8 \mathrm{I})$ \\
\hline
\end{tabular}

Note: ${ }^{a}$ Dialysis vintage is only approximate.
Table 2 Description of the Renal Replacement Therapy $(n=16)$

\begin{tabular}{|c|c|c|}
\hline & ol-HDF & MCO-HD \\
\hline & Mean \pm SD & Mean \pm SD \\
\hline Blood flow $\mathrm{mL} / \mathrm{min}$ (at $30 \mathrm{~min}$ ) & $324 \pm 9.6$ & $323 \pm 10.8$ \\
\hline Dialysate flow $\mathrm{mL} / \mathrm{min}$ & $550 \pm 0$ & $547 \pm 12.5$ \\
\hline UF rate $(\mathrm{L} / \mathrm{h})$ & $0.62 \pm 0.29$ & $0.64 \pm 0.34$ \\
\hline Convection volume & $\begin{array}{l}24.5 \pm 3.5 \text { range: } \\
(16.9-30.6)\end{array}$ & - \\
\hline Hematocrit initial, $\mathrm{AO}$ & $0.333 \pm 0.046$ & $0.329 \pm 0.046$ \\
\hline Dialyzer & Polyflux $2 \mathrm{IOH}$ & Theranova 500 \\
\hline
\end{tabular}

\section{Middle Molecules}

HDF treatment gave a significantly higher RR for cystatin $\mathrm{C}$ (Table 3). The reduction ratio was also higher with HDF for $\beta 2$-microglobulin, myoglobin, and beta-trace-protein, but this did not reach statistical significance.

\section{Large/Mixed Molecules}

No significant difference was seen between treatments for any of the large molecules (Table 3). All large molecules generally showed negative RRs (ie, the concentrations increased during dialysis).

\section{Adverse Effects}

Adverse effects were only recorded during the dialysis sessions. No adverse effects were seen during these treatments.

\section{Descriptive Analysis of RR in Relation to Convection Volume}

A plot of the relation between convection volume and $R R$ for the HDF treatment is displayed in Figure 1. A plot of convection volume during HDF against the difference in $\mathrm{RR}(\Delta \mathrm{RR})$ is displayed in Figure 2.

\section{Discussion}

ol-HDF treatment with Polyflux $210 \mathrm{H}$ had significantly higher RR for cystatin $\mathrm{C}$ compared to MCO treatment with a Theranova 500-dialyzer, during a $4 \mathrm{~h}$ dialysis treatment, with a mean convection volume of $24.5 \mathrm{~L}$ for the $\mathrm{HDF}$, and a mean $\mathrm{Q}_{\mathrm{b}}$ of $324 \mathrm{~mL} / \mathrm{min}$. There was no difference in the RR for smaller or larger molecules.

Our results were in line with some previous studies reporting superior RR for HDF compared to MCO for 
Table 3 Description of Pre- and Post-Dialysis Concentrations, and Reduction Ratios During Dialysis with MCO-HD (Theranova) vs HDF (Polyflux 2IOH)

\begin{tabular}{|c|c|c|c|c|c|c|c|c|}
\hline \multirow[b]{3}{*}{ Small } & \multirow{2}{*}{\multicolumn{2}{|c|}{$\begin{array}{l}\text { Pre-Dialysis } \\
\text { Concentration }\end{array}$}} & \multirow{2}{*}{\multicolumn{2}{|c|}{$\begin{array}{l}\text { Post-Dialysis } \\
\text { Concentration }^{\mathrm{a}}\end{array}$}} & \multicolumn{4}{|c|}{ Reduction Ratio } \\
\hline & & & & & \multicolumn{3}{|c|}{ RR, Mean \pm SD } & \multirow{5}{*}{$\begin{array}{l}\mathrm{P}-\mathrm{val} \\
0.19 \\
0.44 \\
0.87\end{array}$} \\
\hline & HDF & $\mathrm{MCO}$ & HDF & $\mathrm{MCO}$ & HDF & $\mathrm{MCO}$ & $\Delta \mathrm{RR}$ & \\
\hline Urea (mmol/L) & 18.9 & 18.6 & 5.51 & 5.23 & $71.8 \pm 7.1$ & $72.6 \pm 7.8$ & $-0.78 \pm 2.2$ & \\
\hline Creatinine $(\mu \mathrm{mol} / \mathrm{L})$ & 791 & 794 & 277 & 276 & $64.7 \pm 7.9$ & $65.2 \pm 7.5$ & $-0.43 \pm 2.1$ & \\
\hline Phosphate (mmol/L) & 1.57 & 1.49 & 0.667 & 0.619 & $55.8 \pm 11$ & $55.2 \pm 14$ & $0.58 \pm 14$ & \\
\hline \multicolumn{9}{|l|}{ Middle $^{\mathrm{a}}$} \\
\hline$\beta 2$-microglobulin (mg/L) & 24.8 & 25.6 & 7.25 & 7.85 & $70.6 \pm 8.5$ & $68.5 \pm 10$ & $2.10 \pm 4.2$ & 0.061 \\
\hline Cystatin C (mg/L) & 6.94 & 7.02 & 2.21 & 2.38 & $68.1 \pm 7.7$ & $65.8 \pm 8.0$ & $2.38 \pm 2.7$ & $0.0030 * *$ \\
\hline Myoglobin $(\mu g / L)$ & 209 & 203 & 91.1 & 91.6 & $56.2 \pm 10.6$ & $54.0 \pm 9.3$ & $2.11 \pm 5.4$ & 0.14 \\
\hline Beta-Trace (mg/L) & 7.72 & 7.79 & 4.69 & 4.87 & $38.4 \pm 13$ & $35.5 \pm 12$ & $2.91 \pm 12$ & 0.34 \\
\hline Troponin T (ng/L) & 79.9 & 79.4 & 53.7 & 53.5 & $34.2 \pm 10$ & $34.0 \pm 8.2$ & $0.177 \pm 7.4$ & 0.93 \\
\hline \multicolumn{9}{|l|}{ Large/mixed $^{\mathrm{a}}$} \\
\hline Albumin $(\mathrm{g} / \mathrm{L})$ & 34.8 & 34.2 & 36.2 & 34.9 & $-3.7 I \pm 5.2$ & $-2.02 \pm 3.9$ & $-1.69 \pm 7.1$ & 0.37 \\
\hline Transferrin $(g / L)$ & 1.56 & 1.56 & 1.63 & 1.61 & $-3.80 \pm 4.8$ & $-2.61 \pm 4.3$ & $-1.18 \pm 5.9$ & 0.43 \\
\hline $\lg G(g / L)$ & 10.7 & 10.4 & 11.0 & 10.8 & $-3.38 \pm 5.6$ & $-3.92 \pm 4.2$ & $0.539 \pm 6.0$ & 0.73 \\
\hline Transthyretin (Prealbumin) $(\mathrm{g} / \mathrm{L})$ & 0.316 & 0.320 & 0.337 & 0.312 & $-7.88 \pm 18$ & $0.359 \pm 17$ & $-8.23 \pm 23$ & 0.17 \\
\hline Total protein $(\mathrm{g} / \mathrm{L})$ & 63.6 & 63.1 & 65.3 & 64.0 & $-2.65 \pm 5.5$ & $-1.24 \pm 4.1$ & $-1.41 \pm 4.9$ & 0.30 \\
\hline EVF & 0.333 & 0.329 & 0.349 & 0.348 & $-4.88 \pm 5.4$ & $-5.79 \pm 6.4$ & $0.91 \pm 6.1$ & 0.56 \\
\hline
\end{tabular}

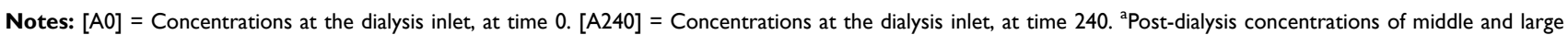
molecules are adjusted for hematocrit according to Schneiditz et al. $\triangle \mathrm{RR}=$ Difference between RRs (HDF-MCO). **Significant using the Bonferroni-corrected threshold for 14 outcomes, $\mathrm{p}=0.0036$.

small middle molecules (such as $\beta 2$-microglobulin), but not for larger middle molecules. ${ }^{10,12,14,26}$ Although our study only showed significantly higher RR with HDF for Cystatin C (13 kDa), the RR was slightly higher also for $\beta 2$-microglobulin $(11 \mathrm{kDa})$, although this was not statistically significant. Comparing our study to two studies with similar convection volumes to our study, which could be expected to show similar results, the study by Kirsch et al showed that HDF had higher RR for $\beta 2$-microglobulin, although MCO was superior for larger middle molecules. ${ }^{10}$ In the study by Reque et al, however, MCO was superior for both $\beta 2$-microglobulin and larger middle molecules, although the difference was only statistically significant for the larger middle molecules. ${ }^{13}$

A difference compared to these studies was the lower $\mathrm{Q}_{\mathrm{b}}$ in our study $\left(\mathrm{Q}_{\mathrm{b}} 324 \mathrm{~mL} / \mathrm{min}\right.$, compared to $\mathrm{Q}_{\mathrm{b}} 400 \mathrm{~mL} / \mathrm{min}$ for Kirsch, ${ }^{10}$ and $\mathrm{Q}_{\mathrm{b}} 350 \mathrm{~mL} / \mathrm{min}$ for Reque ${ }^{13}$ ), which decreases the internal convection volume for $\mathrm{MCO}$, while not affecting the HDF if assuming a fixed convection volume (although the maximal capacity for HDF convection volume is decreased). The convection volume is also dependent on factors such as hematocrit (determining the effective $\mathrm{Q}_{\mathrm{b}}$ ), and protein oncotic pressure, and such factors might differ between the studies, not only depending on dialysis mode and dialyzer type, but also in analytical adjustments done to account for changes in blood viscosity during dialysis. One semi-empirical study has suggested that diffusion, not convection, of middle molecules is actually the main mechanism of removal with MCO dialyzers also for middle molecules. ${ }^{23}$ Potential dialyzer differences in diffusion capacity may therefore also complicate comparisons between studies when different dialyzers have been used for HDF. Dialyzer type for HDF was Polyflux $210 \mathrm{H}$ for both our study and the study by Reque, ${ }^{13}$ while Kirsch et $\mathrm{al}^{10}$ compared with FX CorDiax (Fresenius).

In the studies with very high convection volumes (GarciaPreto et al ${ }^{12}$ and Maudell et $\mathrm{al}^{14}$ ), there was a tendency towards higher RRs for small middle molecules (but not for the largest middle molecules), for HDF compared to MCO, although the differences were large between the 8 different dialysis dialyzer types used for HDF in the study by Maduell, and significantly higher for both 32 -microglobulin and myoglobin only for the dialyzer Elisio19H. ${ }^{14}$ Although the previously cited studies used post-dilutional HDF, a recent study comparing HDF in pre-dilution mode (convection volume 49.91, blood flow $250 \mathrm{~mL} / \mathrm{min}$ ) also found $\mathrm{HDF}$ to be superior for 

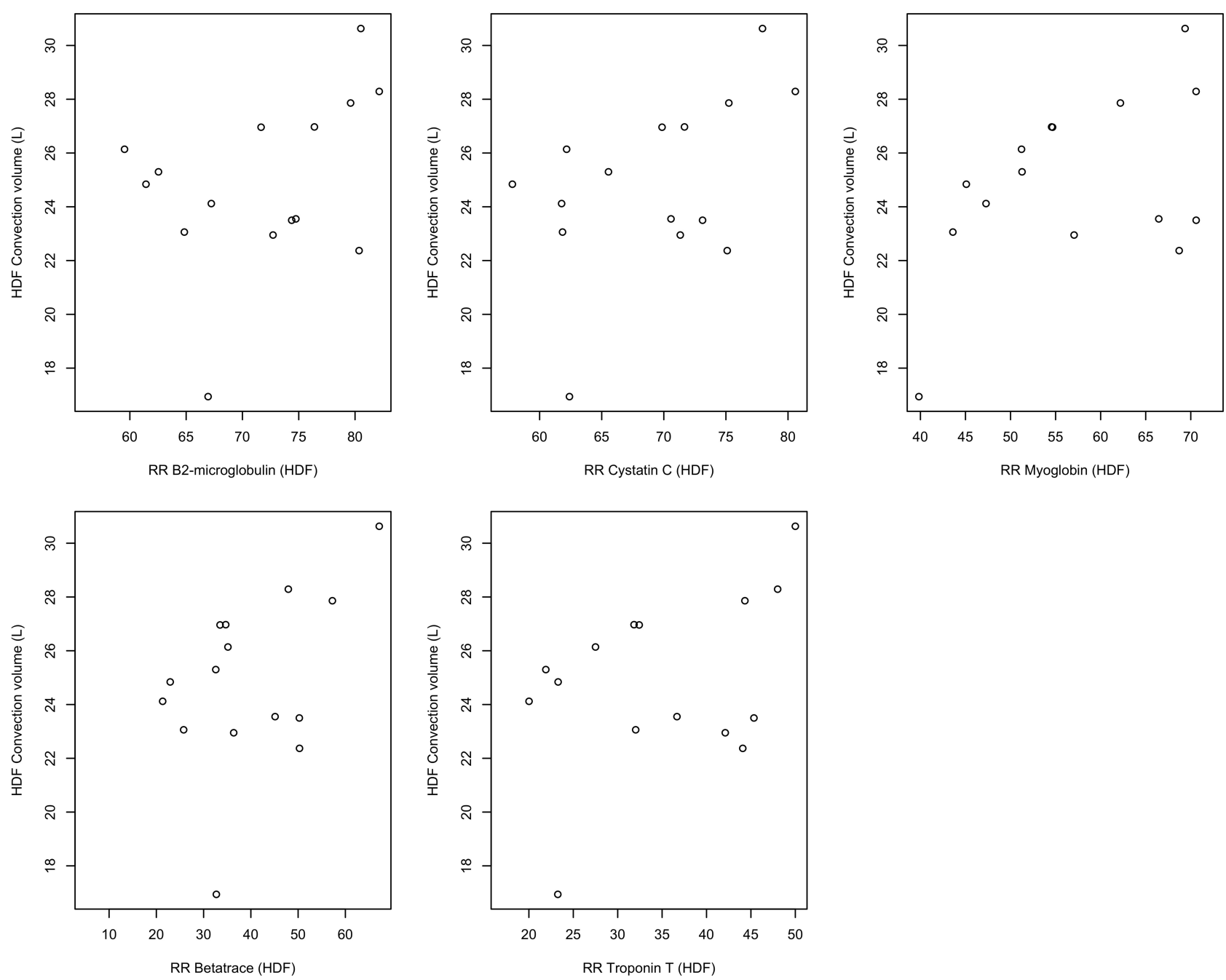

Figure I Convection volume during HDF in relation to RR for HDF.

$\beta 2$-microglobulin (11 kDa) but MCO superior for $\lambda$ free light chains $(45 \mathrm{kDa}){ }^{26}$

Even if large molecules theoretically should not pass the dialysis membrane in significant amounts, protein adsorption on the dialyzer membrane is also a potential mechanism for removal. ${ }^{18}$ In vitro studies of MCO dialyzers have shown that protein fouling greatly decreases the permeability of the dialysis membrane during the first 40 minutes of blood contact. $^{24}$ Also, studies in vitro of HDF-dialyzer (Revaclear) have shown the sieving coefficient for myoglobin to be reduced from $79 \%$ at $15 \mathrm{~min}$ to $67 \%$ at $60 \mathrm{~min}^{25}$ This may be important especially for consideration of alternative dialysis treatments, such as short daily dialysis.

Our study was underpowered for the comparison of the RR of large molecules, but the results are of descriptive interest. Despite hemoconcentration adjustment, there were negative RRs seen for some of the larger molecules (ie, that the concentrations are slightly higher at the end than the beginning of the dialysis session, probably reflecting hemoconcentration), something which suggests that the RR in this range is strongly dependent on very adequate hemoconcentration adjustments. Such analytical method choices, which differ between studies, are important to consider in future comparisons and reviews of study results, especially for the large molecules and the larger middle molecules.

The study was non-randomized, but the potential risk for bias due to this is limited (although not eliminated) in the present study because of two study design features; 1) The cross-over design where people acted as their own controls minimizes bias due to different patient characteristics. 2) It was a controlled study with equal number performing the dialysis treatments in both sequences of intervention, which limits potential period effects.

The study was also non-blinded, a limitation that could be a concern especially for the reporting of adverse effects, but no adverse effects were seen during either treatment. 

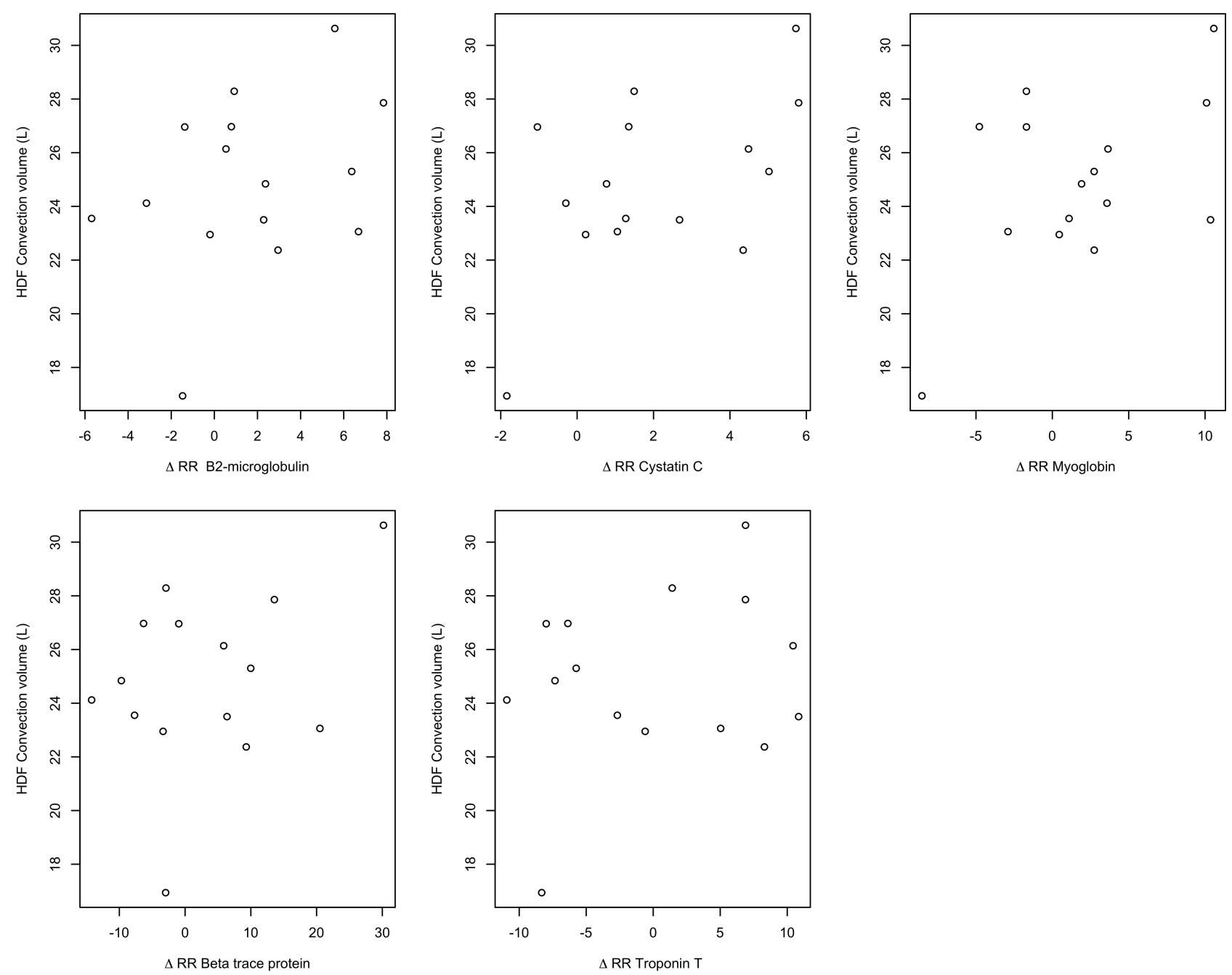

Figure 2 Convection volume during HDF in relation to $\Delta R R$.

Since many factors may influence the dialysis efficiency in addition to the main type of dialysis mode/filter (HDF with conventional high-flux filter vs MCO-HD), it is important with replication of studies across different dialysis settings. We believe our study contributes to the evidence from previous studies comparing HDF with MCO in a dialysis population with well-functioning vascular access (mean convection volume of $24.5 \mathrm{~L}$ for $\mathrm{HDF}$, and mean $\mathrm{Q}_{\mathrm{b}}$ of $324 \mathrm{~mL} / \mathrm{min}$ for $\mathrm{HDF})$. Under these conditions, HDF and MCO overall gave comparable RRs, although HDF slightly outperformed MCO for a small middle molecule. A weakness of our study, however, was that we had no middle molecules in the upper middle molecular range (between $40-60 \mathrm{kDa}$ ), where theoretically the MCO membrane should be more permeable. ${ }^{17}$

\section{Conclusion}

Overall, the RRs were comparable for ol-HDF and MCO-HD. The study found a slightly higher RR of cystatin C (a small middle molecule) for HDF compared to $\mathrm{MCO}$, but no difference in other measured molecules. Whether HDF or MCO is superior for smaller middle molecules is likely to be influenced by the exact blood flows/convection volumes used during the dialysis treatment.

\section{Data Sharing Statement}

Study data will not be publicly archived since ethical permission for this has not been obtained.

\section{Ethics Approval and Informed Consent}

This study was approved by the Lund University Ethical Committee (registration no. 2017/830) and followed the Helsinki declaration. Written informed consent was obtained from all patients in the study. 


\section{Acknowledgments}

Thanks to the dialysis nurses Zoran Malis, Mait Wik and Lotta Åström and the dialysis patients in Malmö who participated in the study, and to Dr Morgan Munson for English language editing.

\section{Funding}

The study was supported by a grant from The Crafoord Foundation (20180536), The Swedish Kidney Association, Stiftelsen för njursjuka, Skåne University Hospital Research Fund, ALF Lund University and the Research Development Council of Region Skåne, Sweden.

\section{Disclosure}

The authors report no conflicts of interest in this work.

\section{References}

1. Vanholder R, De Smet R, Glorieux G, et al. Review on uremic toxins: classification, concentration, and interindividual variability. Kidney Int. 2003;63(5):1934-1943. doi:10.1046/j.1523-1755.2003.00924.x

2. Basile C, Davenport A, Blankestijn PJ. Why choose high volume online post-dilution hemodiafiltration? $J$ Nephrol. 2017;30 (2):181-186. doi:10.1007/s40620-016-0343-0

3. Maduell F, Moreso F, Pons M, et al. High-efficiency postdilution online hemodiafiltration reduces all-cause mortality in hemodialysis patients. J Am Soc Nephrol. 2013;24(3):487-497. doi:10.1681/ ASN.2012080875

4. Nistor I, Palmer SC, Craig JC, et al. Haemodiafiltration, haemofiltration and haemodialysis for end-stage kidney disease. Cochrane Database Syst Rev. 2015;20(5).

5. Storr M, Ward RA. Membrane innovation: closer to native kidneys. Nephrol Dial Transplant. 2018;33(suppl_3):iii22-iii27. doi:10.1093/ ndt/gfy228

6. Ronco C, Marchionna N, Brendolan A, Neri M, Lorenzin A, Martinez Rueda AJ. Expanded haemodialysis: from operational mechanism to clinical results. Nephrol Dial Transplant. 2018;33 (suppl_3):iii41-iii7. doi:10.1093/ndt/gfy202

7. Zweigart C, Boschetti-de-Fierro A, Hulko M, et al. Medium cut-off membranes - closer to the natural kidney removal function. Int $J$ Artif Organs. 2017;40(7):328-334. doi:10.5301/ijao.5000603

8. Krishnasamy R, Hawley CM, Jardine MJ, et al. A trial evaluating mid cut-off value membrane clearance of albumin and light chains in hemodialysis patients: a safety device study. Blood Purif. 2020:1-11.

9. Lorenzin A, Neri M, Lupi A, et al. Quantification of internal filtration in hollow fiber hemodialyzers with medium cut-off membrane. Blood Purif. 2018;46(3):196-204. doi:10.1159/000489993

10. Kirsch AH, Lyko R, Nilsson LG, et al. Performance of hemodialysis with novel medium cut-off dialyzers. Nephrol Dial Transplant. 2017;32(1):165-172.
11. Kirsch AH, Rosenkranz AR, Lyko R, Krieter DH. Effects of hemodialysis therapy using dialyzers with medium cut-off membranes on middle molecules. Contrib Nephrol. 2017;191:158-167.

12. Garcia-Prieto A, Vega A, Linares T, et al. Evaluation of the efficacy of a medium cut-off dialyser and comparison with other high-flux dialysers in conventional haemodialysis and online haemodiafiltration. Clin Kidney J. 2018;11(5):742-746. doi:10.1093/ckj/sfy004

13. Reque J, Perez Alba A, Panizo N, Sanchez-Canel JJ, Pascual MJ, Pons Prades R. Is expanded hemodialysis an option to online hemodiafiltration for small- and middle-sized molecules clearance? Blood Purif. 2019;47(1-3):126-131. doi:10.1159/000493910

14. Maduell F, Rodas L, Broseta JJ, et al. Medium cut-off dialyzer versus eight hemodiafiltration dialyzers: comparison using a global removal score. Blood Purif. 2019;48(2):167-174. doi:10.1159/ 000499759

15. Voigt M, Gebert M, Haug U, et al. Retention of beneficial molecules and coagulation factors during haemodialysis and haemodiafiltration. Sci Rep. 2019;9(1):6370. doi:10.1038/s41598-019-42783-w

16. Belmouaz M, Diolez J, Bauwens M, et al. Comparison of hemodialysis with medium cut-off dialyzer and on-line hemodiafiltration on the removal of small and middle-sized molecules. Clin Nephrol. 2018;89(1):50-56.

17. Wolley M, Jardine M, Hutchison CA. Exploring the clinical relevance of providing increased removal of large middle molecules. Clin J Am Soc Nephrol. 2018;13(5):805-814. doi:10.2215/CJN.10110917

18. Huang Z, Gao D, Letteri JJ, Clark WR. Blood-membrane interactions during dialysis. Semin Dial. 2009;22(6):623-628. doi:10.1111/j.1525139X.2009.00658.x

19. Andrade JD, Hlady V. Plasma protein adsorption: the big twelve. Ann N Y Acad Sci. 1987;516:158-172. doi:10.1111/j.1749-6632.1987. tb33038.x

20. Wellek S, Blettner M. On the proper use of the crossover design in clinical trials: part 18 of a series on evaluation of scientific publications. Dtsch Arztebl Int. 2012;109(15):276-281.

21. Sedgwick P. Multiple hypothesis testing and Bonferroni's correction. BMJ. 2014;349:g6284. doi:10.1136/bmj.g6284

22. Schneditz D, Putz-Bankuti C, Ribitsch W, Schilcher G. Correction of plasma concentrations for effects of hemoconcentration or hemodilution. ASAIO J. 2012;58(2):160-162. doi:10.1097/ MAT.0b013e318243660f

23. Macias N, Vega A, Abad S, et al. Middle molecule elimination in expanded haemodialysis: only convective transport? Clin Kidney J. 2019;12(3):447-455. doi:10.1093/ckj/sfy097

24. Boschetti-de-Fierro A, Voigt M, Storr M, Krause B, Membranes: MCO. Enhanced selectivity in high-flux class. Sci Rep. 2015;5:18448. doi:10.1038/srep18448

25. Hulko M, Haug U, Gauss J, Boschetti-de-Fierro A, Beck W, Krause B. Requirements and pitfalls of dialyzer sieving coefficients comparisons. Artif Organs. 2018;42(12):1164-1173. doi:10.1111/ aor. 13278

26. Kim TH, Kim S-H, Kim TY, et al. Removal of large middle molecules via haemodialysis with medium cut-off membranes at lower blood flow rates: an observational prospective study. BMC Nephrol. 2020;21:2. doi:10.1186/s12882-019-1669-3
The International Journal of Nephrology and Renovascular Disease is an international, peer-reviewed open-access journal focusing on the pathophysiology of the kidney and vascular supply. Epidemiology, screening, diagnosis, and treatment interventions are covered as well as basic science, biochemical and immunological studies. The manuscript management system is completely online and includes a very quick and fair peer-review system, which is all easy to use. Visit http://www.dovepress.com/testimonials.php to read real quotes from published authors. 